\title{
Alteridade no multiculturalismo: representações sociais e dialogicidade de professores de escolas públicas de São Paulo
}

\author{
Alterity in multiculturalism: dialogicity and social representations of teachers from \\ the public schools of São Paulo
}

Monica Ribeiro Nunes

Mestre em Educação

Universidade Cidade de São Paulo - UNICID.

São Paulo, SP - Brasil.

network@visarmc.com.br

Adelina Novaes

Doutora em Educação Fundação Carlos Chagas - FCC.

São Paulo, SP - Brasil. anovaes@fcc.org.br

Resumo: O estudo visou compreender as representações sociais de professores de Ensino Fundamental $2\left(6^{\circ}\right.$ ao $9^{\circ}$ ano) da rede pública municipal de educação de São Paulo sobre o estudante imigrante. A escola eleita distinguiu-se pelo multiculturalismo, visto que $10 \%$ do total de seu alunado é composto por estudantes imigrantes da Argentina, Bolívia e Chile. A abordagem dialógica da teoria das representações sociais foi orientadora da sistematização e análise das informações produzidas nas observações in loco e nos dois grupos focais realizados. As representações acerca dos estudantes imigrantes ganharam destaque quando em confrontação com as representações sobre os estudantes brasileiros, e jogam luz, sobretudo, nos alunos de origem boliviana.

Palavras chave: representações sociais; alteridade; dialogicidade; multiculturalismo.

Abstract: The study aimed to understand the social representations of elementary school teachers (6th to 9th grade) from the municipal public education system in São Paulo about the immigrant student. The chosen school distinguished itself by its multiculturalism, as $10 \%$ of its students are made up of immigrants from Argentina, Bolivia and Chile. The dialogic approach of social representations theory guided the systematization and analysis of the information produced in the observations in loco and in the two focus groups meeting that were made. Representations about immigrant students stood out in comparison with representations about Brazilian students, and, above all, highlighted students of Bolivian origin.

Keywords: social representations; alterity; dialogicity; multiculturalism.

Cite como

(ABNT NBR 6023:2018)

NUNES, Monica Ribeiro; NOVAES, Adelina. Alteridade no multiculturalismo: representações sociais e dialogicidade de professores de escolas públicas de São Paulo. Dialogia, São Paulo, n. 40, p. 1-21, e20633, jan./abr. 2022. Disponível em: https://doi.org/10.5585/40.2022.20633.

American Psychological Association (APA)

Nunes, M. R., \& Novaes, A. (2022, jan./abr.) Alteridade no multiculturalismo: representações sociais e dialogicidade de professores de escolas públicas de São Paulo.. Dialogia, São Paulo, 40, p. 1-21, e20633. https://doi.org/10.5585/40.2022.20633. 


\section{Introdução}

De acordo com o último anuário do Sistema Nacional de Cadastramento de Estrangeiros que consta no OBMigra (CAVALCANTI; OLIVEIRA; MACEDO, 2020) disponível, apenas em 2019 foram cadastrados oficialmente 82.552 imigrantes no Brasil. Como efeito dos fluxos populacionais na última década ${ }^{1}$, o sistema educacional brasileiro recebeu milhares de alunos de diversas nacionalidades (BRASIL, 2021).

Nesse contexto, pelo cadastro da Secretaria da Educação do Estado de São Paulo, em 2019, foram registrados 11.905 alunos imigrantes (apenas nas escolas estaduais). Os alunos nessa rede estavam distribuídos nas 91 Diretorias de Ensino, sendo 5.022 bolivianos, 1.307 japoneses, 594 angolanos, 998 haitianos, 433 paraguaios, 410 peruanos, 401 colombianos, 395 venezuelanos, 327 portugueses, 322 argentinos e 1.696 de outras nacionalidades (SÃO PAULO, 2019).

Diante desse fenômeno imigratório, a pesquisa ora relatada buscou compreender as representações sociais de professores sobre os alunos imigrantes em um ambiente escolar de multiculturalismo. Para isso, o estudo amparou-se na abordagem dialógica da Teoria das Representações Sociais (TRS), ao dedicar atenção à tríade: eu - outro - objeto/mundo (MARKOVÁ, 2006, 2017), que também pode ser compreendida como Ego (professores) - Álter (alunos) - Objeto² (conteúdos curriculares) (NOVAES; ORNELLAS; ENS, 2017).

\section{$1 \mathrm{O}$ conceito de multiculturalismo adotado}

De acordo com Silva e Brandim (2008), o multiculturalismo, enquanto campo de estudo, se instaura na metade do século XX nos Estados Unidos, motivado pelos debates acerca da questão racial, no que concerne aos direitos civis dos afro-americanos. Os primeiros a inserirem esse debate na academia foram docentes universitários afro-americanos de ciências sociais. A partir dos anos 1970, os debates passaram contemplar também mulheres, estudantes de baixa renda e alunos com necessidades especiais. Nas décadas seguintes o estudo do multiculturalismo expandiu-se a ponto de entrar no currículo das universidades, valorizando o estudo da pluralidade e das diferenças culturais. No Brasil, o movimento chegou uma década depois e as discussões nas universidades se intensificaram nos anos 90, apesar de os protestos em relação aos afro-brasileiros terem começado nos anos 50 (GONÇALVES; SILVA, 2001).

O multiculturalismo não é, portanto, recente, mas foi agudizado nos últimos anos, mostrando-se imperativo pensá-lo no contexto escolar. Nas palavras de Candau (2002):

1 No período de 2011 a 2019 foram registrados no Brasil 1.085 .673 imigrantes (CAVALCANTI; OLIVEIRA; MACEDO, 2020).

2 Há grande diversidade na literatura quanto ao emprego dos termos dos elementos constantes da tríade dialógica. Neste trabalho foram respeitados os termos que constavam da referência consultada. 
[...] a nossa formação histórica está marcada pela eliminação física do "outro" ou por sua escravização, que também é uma forma violenta de negação de sua alteridade. os processos de negação do "outro" também se dão no plano das representações e no imaginário social. neste sentido o debate multicultural na América Latina nos coloca adiante da nossa própria formação histórica, da pergunta sobre como nós construímos socio culturalmente, o que negamos e silenciamos, o que afirmamos, valorizamos e integramos na cultura hegemônica. (CANDAU, 2002, p. 2).

Ao estudo do multiculturalismo se impõe o desafio de lidar com preconceitos e visões essencializadas das identidades e das diferenças. Para isso é preciso atentar para as narrativas, para os discursos, para as múltiplas vozes que os sujeitos sociais constroem. Assim afirma Hooks (2013, p. 57):

\begin{abstract}
[...] as adoções do multiculturalismo obrigam os educadores a centrar sua atenção na questão da voz. Quem fala? Quem ouve? E por quê? Cuidar para que todos os alunos cumpram responsabilidades de contribuir para o aprendizado na sala de aula não é uma abordagem comum no sistema que Freire chamou de "educação bancária", onde os alunos são encarados como meros consumidores passivos. Uma vez que tantos professores ensinam a partir desse ponto de vista, é difícil criar uma comunidade de aprendizado que abrace plenamente o multiculturalismo. (HOOKS, 2013, p. 57).
\end{abstract}

Freire (1997) deu destaque ao multiculturalismo quando afirmou a necessidade de dar permissão ao convívio dos diferentes. Para ele, quando a convivência não se dá de forma espontânea, é preciso mobilizar, de maneira intencional:

\footnotetext{
As chamadas minorias [...] precisam reconhecer que, no fundo, elas são a maioria. O caminho para assumir-se como maioria está em trabalhar as semelhanças entre si e não só as diferenças e assim, criar a unidade na diversidade, fora da qual não vejo como aperfeiçoar-se e até como construir-se uma democracia substantiva, radical. (FREIRE, 1997, p. 154).
}

O conceito de multiculturalismo possui distintas definições e perspectivas, podendo ser estudado por meio das diferenças de classes e de situações conflitantes, a exemplo do reconhecimento de grupos sociais, como os imigrantes (MCLAREN, 2000; GONÇALVES; SILVA, 2001; CANEN; CANEN, 2005), nesse sentido, o estudo do multiculturalismo como forma de contribuir para a emancipação social e cultural é muitas vezes nomeado como multiculturalismo crítico ou de resistência, visto que:

1) Ratifica um compromisso sócio-político de transformação, sem permitir a uma acomodação da situação vigente; 2) evidencia e apoia a transformação das e nas relações sócio-culturais e institucionais onde se entende que os significados nascem; 3) não 
compreende uma cultura se ela não for de conflitos; 4) fortalece a ideia que a diversidade deve ser valorizada dentro de uma política crítica e compromisso com a justiça social. (MCLAREN, 1997, p. 123).

McLaren (2000) descreve ainda uma forma de multiculturalismo que está além da resistência, o multiculturalismo revolucionário, que procura analisar a sociedade e seus mecanismos de desenvolvimento de desigualdades, de pluralidades e reconhecimento de identidades, um multiculturalismo que percebe um desenvolver das desigualdades induzidas por vários setores, destacando o capitalismo de produção como um impulsionador de diferenças.

Um dos papéis do multiculturalismo revolucionário (além de trazer à tona questões de ordem social, cultural e histórica) é o de transformar atitudes discriminatórias, ao reconstruir estruturas tanto nas culturas, quanto na sociedade. Em outros termos, é ter a ousadia de promover uma reforma à democracia capitalista e reconstruir a ordem social do ponto de vista dos desprivilegiados, ou como dizem o próprio McLaren (2000) e Freire (2005), dos oprimidos.

O multiculturalismo, presente nas escolas, é orgânico e está em constante movimento. Nesse sentido, trabalhar o multiculturalismo em educação requer a promoção de questionamentos que partam de teorias sociais, mas que envolvam um debate político e prático, ao colocar à prova preconceitos em busca de estratégias pedagógicas:

\begin{abstract}
Além disso, falando em mais de um idioma e frequentemente servindo como intérpretes para as famílias, as crianças multilíngues demonstram a capacidade de adotar normas culturais diferentes e de se comunicar dentro e através das culturas domésticas / dominantes. Despertar conscientemente as diferenças e semelhanças entre a cultura do lar e as culturas sociais mais amplas contribui para o aumento da consciência das nuances pragmáticas pelas crianças e permite que elas naveguem com êxito em uma série de contextos culturais. ${ }^{3}$ (BAILEY; OSIPOVA, 2016, p. 22, tradução nossa).
\end{abstract}

Multiculturalismo é, portanto, um "conceito polissêmico e polifônico por excelência" (CANEN, 2015, p. 98). Significa dizer que o multiculturalismo envolve visões epistemológicas diferenciadas e interpretações plurais do contexto social e também do conceito de indivíduo (CANEN, 2015, p.100). Nesses contextos, diversas vozes e culturas coabitam (CANEN, 2015, p. 101).

Ao lidar com o múltiplo, o diverso e o plural, o multiculturalismo encara as identidades plurais como a base de constituição das sociedades. Leva em consideração a pluralidade de raças, gêneros, religiões, saberes, culturas, linguagens e outras características

\footnotetext{
${ }^{3}$ Tradução livre de: "Moreover, speaking more than one language and frequentlyserving as interpreters for theis families, multilingual children demonstrate na ability to adopt differing cultural norms and communicate within and across the home/dominat cultures. Gorwing up acutely conscious os the diferences and similarities between the home culture and wider societal cultures contyributes to multilinguakl children's heightened awarenessof pragmatic nuances and allows them to succesfully navigate a host of cultural contexts".
} 
identitárias para sugerir que a sociedade é múltipla e que tal multiplicidade deve ser incorporada em currículos e práticas pedagógicas. (CANEN, 2015, p. 94).

Nesse sentido, aproximar a TRS da concepção de multiculturalismo de Canen (2015), eleita para este estudo, pareceu possível, visto que a TRS tem um caráter interdisciplinar:

É por isso que a aproximação das representações sociais constitui um aparato heurístico teórico para aprofundar o conhecimento da realidade social, bem como para oferecer os meios de intervenção sobre estes últimos, em relação às demais disciplinas. ${ }^{4}$ (JODELET; TAPIA, 2000, p. 9, tradução nossa).

\section{Contribuições da teoria das representações sociais para a pesquisa}

Conhecer as razões da manutenção das representações sociais permite a contestação do status quo e a promoção da mudança no plano do senso comum, visto que representações sociais são teorias emergentes do senso comum, elaboradas coletivamente nas interações sociais, num determinado tempo histórico, em uma cultura e espaço geográfico, na tentativa de tornar o diferente mais próximo da realidade. ${ }^{5}$

Nas palavras Howarth e Andreouli (2005, p. 5), "todas as representações contêm as "sementes da mudança", se considerarmos a habilidade de debater e argumentar."”

No processo comunicacional, o sujeito social elabora o conhecimento e renova ideias que circulam no cotidiano da sociedade, co-construindo representações sociais:

[...] o Eu e o(s) Outro(s) (ou o Ego-Álter) são mutuamente interdependentes em e pela interação. O Ego-Álter gera conjuntamente sua realidade social - objetos de conhecimento, crenças ou imagens. Aqui já temos a base da interação triangular: EgoÁlter-Objeto na TRS e na teoria da inovação das minorias. (MARKOVÁ, 2017, p. 117).

Afinadas à concepção de tríade dialógica (MARKOVÁ, 2006, 2017), as noções de alteridade e identidade (JODELET, 2002), foram levadas em conta na compreensão dos processos relacionais, uma vez que identidade e alteridade são processos inseparáveis. Em outros termos, "O outro e o [eu] mesmo são construção recíproca que se desvela ao longo de situações históricas” (ARRUDA, 2002, p. 18).

A alteridade resulta das relações de aceitação e exclusão, como Jodelet (2002, p. 48) afirma: “[...] a alteridade é produto de duplo processo de construção e de exclusão social que

\footnotetext{
4 Tradução livre de: "Es por esto que la aproximación de las representaciones sociales constituye un aparato teórico heurístico para profundizar el conocimiento de la realidad social, así también para ofrecer los medios de intervención sobre esta última, con relación a las otras disciplinas".

${ }^{5}$ Pessoas e grupos criam representações no decurso da comunicação e da cooperação. Representações, obviamente, não são criadas por um indivíduo isoladamente. Uma vez criadas, contudo, elas adquirem uma vida própria circulam, se encontram, se atraem e se repelem e dão oportunidade ao nascimento de novas representações, enquanto velhas representações morrem. (MOSCOVICI, 2013, p. 41).

${ }^{6}$ Tradução livre de: "all representations contain the 'seeds of change' insofar as the ability to debate and argue."
} 
indissoluvelmente ligados como os dois lados duma mesma folha, mantém sua unidade por meio dum sistema de representações".

O conceito de alteridade na psicologia social, em especial na TRS, está anelado ao plano social. Essa relação do eu e do outro, do ego e do álter, "[...] a alteridade não aparece com o um atributo que pertenceria à essência do objeto visado, mas sim como uma qualificação que lhe é atribuída do exterior. É um substantivo que se elabora no seio de uma relação social e em torno duma diferença”". (JODELET, 2002, p. 51).

No que concerne especificamente ao estrangeiro, os processos identitários, bem como os de alteridade, podem transitar dinamicamente entre dois polos, desde uma identificação total à uma alteridade radical.

\footnotetext{
Da combinação de proximidade e de distância - e da tensão existente entre essas duas dimensões - resultam um certo número de consequências que afetam relação do estrangeiro com o grupo e o modo como este o trata. Sem raízes no interior do grupo [...] o estrangeiro não compartilha dos mesmos particularismos e das mesmas parcialidades nem do mesmo apego às tradições, o que autoriza uma atitude de “objetividade", que é uma liberdade. [...] Ademais pela ausência da ligação orgânica e pela mobilidade do estrangeiro, a relação que o grupo mantém com ele apresenta um caráter abstrato: ele é próximo por partilhar características gerais (natureza humana, estatuto, profissão), mas não de diferenças especificas ao grupo. Daí uma relação ao mesmo tempo calorosa, em razão da comunidade que gera, que une o estrangeiro ao grupo, e fria em razão de um sentimento de contingência dessa relação, da distância introduzida pela origem estrangeira que ele divide de outros. (JODELET, 2002, p. 57).
}

Ao construir uma teoria dedicada à compreensão das configurações de saberes sociais, Moscovici (2013) ofereceu um instrumental de constructos que encerra potencial para a compreensão dos processos de identidade e alteridade (NOVAES, 2006) e contribui sobremaneira para o campo educacional (NOVAES, 2015). Isso ocorre porque a TRS permite a análise de fenômenos sociais em mudança, contribuindo para compreensão de uma multiplicidade de problemas do dia a dia, nos quais os sujeitos sociais estão inevitavelmente envolvidos (CARRERAS et al., 2017, p. 13-14).

Com base na tríade dialógica é possível afirmar que o aluno imigrante tem muito a contribuir para as dinâmicas de sala de aula, assim como Freire (2005) alertou para o protagonismo do educando. Dessa forma, a dialogicidade na perspectiva freireana $(1997,2006)$ mantém relações com aquela debatida por Marková $(2006,2017)$. Ambas as abordagens dialógicas contribuíram para o desenvolvimento da pesquisa, sobretudo por considerarem a possibilidade de mudança social. Para ambos, o diálogo oportuniza a ação de indivíduos transformadores, porque aqueles que consideram os outros por meio de um ethos dialógico admitem a "inconclusão" permanente que perfaz o movimento na história (FREIRE, 2002, p. 136). 


\section{Trajetória metodológica empreendida}

A Escola Municipal de Ensino Fundamental (Emef) eleita como lócus do estudo distinguiuse pelo multiculturalismo ${ }^{7}$, visto que aproximadamente cem discentes, o que equivale a cerca de um quarto de seu alunado, era composto por estudantes imigrantes da Argentina, Bolívia e Chile (SÃO PAULO, 2017). A unidade escolar participa da Diretoria Regional Jaçanã/Tremembé, que consiste na segunda diretoria em número de estudantes imigrantes matriculados, com aproximadamente 805 alunos (SÃO PAULO, 2017).

Fundada em treze de junho de 1988, foi a primeira escola de alvenaria da região (SÃO PAULO, 2017). A Emef está localizada em área de vulnerabilidade baixa, na mesma quadra de outros órgãos públicos. Possui uma quadra coberta e duas descobertas, área verde extensa, uma estufa onde funciona a horta escolar, além de dois prédios com as salas de aula. Conta com biblioteca, sala de apoio para alunos e uma professora designada para atividades extras, sala de informática, sala de artes, sala de professores, elevadores para o trânsito dos alunos cadeirantes, refeitório amplo e arejado com espaço compartilhado para leitura dispondo de livros em português e espanhol. A escola ainda conta com painéis nos muros internos e externos pintados por um artista plástico boliviano e por um artista brasileiro em conjunto com os alunos da escola.

As salas de aula possuem excelente iluminação e são bem arejadas com numerosas janelas e ventiladores e sua dimensão permite que os professores façam movimentos com as cadeiras de forma a mudar o layout da sala. Cada sala de aula possui uma caixa com livros que faz parte do projeto de incentivo à leitura na língua portuguesa.

A Emef contava em 2018 com 810 alunos matriculados, dos quais aproximadamente 8\% eram de nacionalidade estrangeira, segundo dados fornecidos pela Secretaria Municipal de Educação. Em 2019, contava com 809 alunos matriculados, sendo 10\% do alunado formado por imigrantes, além de 63 professores, 15 funcionários administrativos e 13 funcionários terceirizados e desenvolvia quinze projetos em parceria com outras instituições (todos realizados no contraturno escolar).

\subsection{Observação assistemática}

\footnotetext{
${ }^{7}$ Apesar do foco na imigração, entendeu-se que o multiculturalismo não é um fenômeno exclusivo da transferência (voluntária ou involuntária) de pessoas a outros países, mas da vivência de sujeitos sociais em âmbitos culturais distintos, o que pode ocorrer entre concidadãos. Mesmo que a literatura também apresente o termo multiculturalidade, foi mantido multiculturalismo por ser o mais frequente na bibliografia especializada.
} 
A técnica de observação permite que vários aspectos sejam contemplados a exemplo de comportamentos, fatos e cenários (ALVES-MAZZOT'TI; GEWANDSZNAJDER, 2001, p. 164) e apresenta potencialidades destacando-se: (a) a veracidade das respostas dos sujeitos é mais fácil de ser percebida pois não existe a preocupação de dar as respostas certas; (b) que é possível pontuar os comportamentos "não-intencionais ou inconscientes e explorar tópicos que os informantes não se sentem à vontade para discutir” (ALVES-MAZZOTTI; GEWANDSZNAJDER, 2001, p. 164); (c) pode-se registrar os fatos e comportamentos no momento e no espaço que estão acontecendo.

Neste trabalho, os registros das observações assistemáticas foram feitos nos dias 18 de abril, 16 de maio, 22 de agosto, 12 de dezembro de 2018 e 8 de junho de 2019, além de mais duas visitas com o objetivo de realizar sessões de grupo focal (detalhadas na seção seguinte). As nove visitas à escola foram registradas no formato de jornal de pesquisa ${ }^{8}$.

\subsubsection{Visita 1: Inauguração da biblioteca}

A presença do mesmo grupo gestor por mais de vinte anos contribuiu para que a escola ganhasse credibilidade no bairro. Nesta primeira visita, a pesquisadora participou da reinauguração da biblioteca, momento em que tomou conhecimento da história da professora que empresta o nome ao espaço. A referida professora possui ascendência japonesa e trabalhou por 38 anos na escola como docente de Língua Portuguesa e Assistente de Diretor. Ela se transformou em um dos ícones para a abertura da escola para alunos imigrantes e suas famílias. Foi observado clima amistoso entre os professores e respeito pela docente que recebeu a homenagem, que foi aplaudida e abraçada por todos, após um discurso de poucas palavras de agradecimento.

A primeira visita foi marcada por grande acolhimento. A coordenadora pedagógica deu espaço na Jornada Especial Integral de Formação (JEIF) para que a pesquisa fosse apresentada. Foram compartilhados projetos que os professores do ensino fundamental 2 estavam realizando. Muitos dos projetos estavam vinculados à importância da leitura do dia a dia dos alunos. Outros projetos estavam ligados à horta que também estava sendo recém-inaugurada.

Nesse dia, a pesquisadora não observou nenhum comentário ou projeto ligado aos alunos imigrantes, excetuando-se um conduzido pelo professor de educação física durante o contraturno. Observou também que "imigração", "imigrante" ou "refugiado" não foram palavras citadas na

\footnotetext{
${ }^{8}$ Com o intuito de justificar o emprego da expressão "jornal de pesquisa" ao invés de "diário de pesquisa" ou "diário de campo", o estudo baseou-se nos conceitos apresentados por Barbosa (2010). O autor estabelece que ambos permitem o registro pessoal, amoroso ou de outra ordem, mas o "diário", muito comum entre os adolescentes, tem um caráter privado, e o "jornal" visa tornar as anotações públicas (BARBOSA, 2010, p. 26-27).
} 
reunião. Aparentemente, os estudantes parecem ser vistos como membros de um mesmo coletivo, sem distinção de origem.

$\mathrm{Na}$ ocasião foi possível fazer observação no pátio da escola, no horário do intervalo. Existiam grupos de estudantes que se relacionavam bem com os alunos imigrantes e outros que ainda se mantinham afastados. Pôde-se observar ainda alguns grupos de alunos imigrantes isolados, facilmente notados por estarem falando na língua de seus país de origem (no caso deles, língua espanhola). Foi observado também que as meninas pareciam possuir mais resistência de se relacionar com os alunos imigrantes. Chamou a atenção, naquele momento no pátio, haver somente uma menina afrodescendente entre os alunos imigrantes. Também não foi observada nenhuma interferência de professor ou professora em relação ao fato de os alunos não interagirem.

Outro ponto de destaque foi que, dependendo da atividade, como o jogo de futebol improvisado em uma das quadras, havia interação entre meninos brasileiros e meninos imigrantes. Quanto às meninas, não foi identificada qualquer atividade que as unisse ou afastasse. No entanto, ficou bem nítido que as meninas brasileiras praticamente não se comunicam com os alunos imigrantes.

\subsubsection{Visita 2: Projeto de intercâmbio entre culturas, línguas e pessoas}

O motivo da segunda visita foi conhecer o "Projeto de intercâmbio entre culturas, línguas e pessoas", que o professor de educação física estava desenvolvendo com alunos hispanoablantes e alunos brasileiros, com o objetivo de ampliar a interação, o empoderamento dos alunos imigrantes e a aprendizagem de línguas nas duas direções: português-espanhol e espanhol-português. $O$ projeto consistia em, além de aprender a ambas as línguas, dar a oportunidade aos alunos de conhecer culturas diferentes e desenvolver o entendimento e o respeito à diversidade étnica na qual está inserida a escola.

O projeto foi conduzido em duas aulas por semana, de 50 minutos cada. Cada encontro começava numa sala de aula com as cadeiras em círculo e o professor iniciava uma roda de conversa (baseado na roda dialógica da pedagogia freireana).

Naquele dia, eles estavam planejando os próximos eventos da escola e como iriam participar. Estava sendo anunciado também que, durante o projeto, eles receberiam visitas de profissionais que iriam conversar em espanhol e apresentar alguma oficina para enriquecer ainda mais os encontros. Depois desta roda de conversa, os alunos foram para o pátio.

Foi observado que os meninos se sentaram de um lado e as meninas de outro. Destaca-se que os alunos brasileiros e os imigrantes se misturaram, só se dividiram por gênero. Tudo isso 
ocorreu de forma espontânea. Após a roda de conversa, quando a pesquisadora foi apresentada, o professor fez algumas sugestões de atividades. Umas das atividades propostas foi um jogo com bola em quadra, para aprender os números em espanhol. $\mathrm{Na}$ atividade, foram formados espontaneamente grupos separados de meninos e meninas.

Em encontros posteriores, a pesquisadora soube que o projeto foi descontinuado no final do ano letivo, uma vez que o professor foi trabalhar como técnico da Secretaria Municipal de Educação, após aprovação em concurso interno da Rede.

\subsubsection{Visita 3: sensibilização para a pesquisa}

A terceira visita teve o objetivo de apresentar novamente a pesquisa, em nova reunião da JEIF. Na ocasião, os aspectos metodológicos foram expostos mais detidamente. Esse momento foi essencial para observação das dinâmicas dos professores com mais tempo e com menos tempo de docência. $\mathrm{Na}$ ocasião, a pesquisadora explicou como funcionariam as duas sessões de grupo focal e sugeriu as datas. Também explicou no que consistia em um grupo focal e as professoras pareceram mais interessadas do que os professores. Um dos professores avisou que não poderia participar do grupo focal por questões pessoais. Outro professor expressou sua opinião e receio e disse que não iria se comprometer por conta do quadro político, na época ainda muito indefinido, e ele preferiria se isentar da pesquisa. A proposta foi aceita pelos demais professores.

\subsubsection{Visita 4: observação da mudança de turno}

$\mathrm{Na}$ visita dedicada à observação da troca de turno, buscou-se elementos acerca da movimentação dos estudantes e dos pais e responsáveis. Percebeu-se que os pais dos alunos imigrantes parecem estar presentes no cotidiano escolar dos seus filhos. Eles estavam na secretaria da escola tirando dúvidas de atividades e perguntando acerca dos seus filhos, outros estavam procurando saber sobre o curso de português para estrangeiros que a escola estava oferecendo.

$\mathrm{Na}$ data, ocorreu também o encerramento do "Projeto de intercâmbio entre culturas, línguas e pessoas". Os alunos estavam confeccionando piñatas de Natal, uma espécie de enfeite recheado de doces e cobertos com papeis coloridos. A pesquisadora acompanhou toda a movimentação do encerramento. Além da confecção das piñatas, também aconteceu o "amigo chocolate de Natal"’ e a comemoração dos aniversariantes do mês.

\footnotetext{
${ }^{9}$ Amigo chocolate de Natal é uma variação temática do amigo secreto, que consiste em uma brincadeira tradicional de troca de presente mediante ao sorteio de nomes.
} 
O professor do projeto conduziu o encerramento com a presença da coordenadora. A conversa com o professor responsável pelo projeto foi proveitosa para compreender o sucesso no cumprimento dos objetivos propostos: os alunos imigrantes estavam mais participativos no ambiente escolar e percebendo-se valorizados pelo ensino da língua espanhola aos colegas brasileiros; por sua vez, os alunos brasileiros evidenciavam respeito e consideração às diferentes culturas.

O que pode exemplificar o processo foi que, quando um estudante novo chegava, logo um aluno do projeto era colocado como intérprete seja de língua portuguesa ou de língua espanhola. Os professores relataram ao professor do projeto que esta metodologia de integração sempre pareceu muito bem-sucedida. Os alunos que participaram do projeto tiveram um aproveitamento e uma participação ainda maior nas aulas regulares. O projeto não conseguia receber mais do que trinta alunos em sala de aula e o número precisava ser metade de alunos imigrantes e metade de alunos brasileiros, além de meninos e meninas serem em igual quantidade. Por esse motivo muitos alunos que gostariam de participar ficaram de fora. Por ser um projeto específico desse professor, e não havendo um envolvimento dos demais colegas, quando o docente foi transferido para a Secretaria, o projeto seria descontinuado. A escola possuía outros projetos como banda, coral e dança, mas a adesão dos alunos imigrantes a essas atividades é de menos de cinco por projeto, além da participação ser em sua maioria das meninas.

\subsubsection{Visita 5: retomada das conversas para dar início aos dois grupos focais}

$\mathrm{Na}$ visita dedicada à retomada das atividades de pesquisa (após as férias de verão), foram definidas as datas das sessões de grupo focal e realizadas observações. A coordenadora ressaltou que conversaria com os professores e que a adesão ao grupo focal seria totalmente espontânea. A pesquisadora concordou e ficou aguardando os nomes dos professores que participariam.

Ao retornar à escola, a pesquisadora ficou ciente de que seria dada continuidade ao "Projeto de intercâmbio entre culturas, línguas e pessoas", porém com algumas modificações. Mesmo à distância, o professor dava suporte a duas estagiárias de cursos de Letras da Universidade de São Paulo (USP), que conduziram o projeto uma vez por semana, para que os alunos continuassem com suas atividades, mesmo que de maneira reduzida.

Destaca-se que nenhuma professora ou professor da equipe docente da Emef assumiu o projeto. A coordenadora está apoiando este novo formato e relatou que os alunos estão frequentando. Mencionou também que ainda não tinham desenvolvido uma avaliação deste novo 
formato. E relatou que os alunos frequentemente perguntavam pelo professor que era líder do projeto e quando que ele visitaria a escola.

\subsubsection{Visita 6: grupo focal cancelado por falta de quórum}

Foi marcada sessão de grupo focal para o dia 28 de março de 2019, com docentes com mais de 10 anos de carreira, no horário da JEIF. Nesse dia, apenas uma das professoras, que depois participou do grupo focal em $1^{\circ}$ de abril de 2019, compareceu. Duas professoras chegaram a entrar na sala, mas avisaram que não poderiam ficar porque tinham que elaborar um relatório e que usariam aquele tempo para isso. As demais não foram e relataram posteriormente para a coordenadora que tinham marcado médico. A única professora que compareceu estava voltando de licença médica e se comprometeu que iria incentivar as colegas a participar numa próxima data.

\subsubsection{Visita 7: observação da festa Junina: interação dos pais, alunos e professores da Emef}

Observou-se a presença de muitos pais com seus filhos na festa junina da escola, todos interagindo e participando intensamente. A escola havia sido pintada recentemente por um artista plástico da comunidade juntamente com os alunos, que elaboraram novos painéis, com novas cores, nos muros da escola. Os painéis são expressão de uma aproximação maior com o dia a dia escolar, com imagens que representam a migração e a imigração no meio do pátio central.

Pode ser observado que as famílias dos alunos imigrantes eram em maior número, os alunos brasileiros de idade acima dos 11 anos estavam em sua metade desacompanhados enquanto os alunos imigrantes, independentemente de suas idades, estavam com a família completa (pode ser visto que muitos estavam não somente com pai e mãe, mas com avós, tios e primos). Outro aspecto a se destacar é que eles se deslocavam pela escola juntos.

\subsection{Grupo focal na perspectiva dialógica}

As sessões de grupo focal permitem a produção de informações, a partir da mediação de um facilitador, de forma não estruturada, com um pequeno grupo de participantes. Por essas características, 
[...] uma das principais razões de usar grupos focais para estudar as representações sociais ou compartilhar socialmente um conhecimento é que eles podem ser comparados a conversas comuns. Isso é: eles nos permitem entender o modo em que as diferentes perspectivas se opõem entre si, são negociadas e co-construídas. ${ }^{10}$ (MARKOVÁ et al., 2007, p. 103, tradução nossa).

Foram realizadas duas sessões de grupo focal de aproximadamente 60 minutos com professores especialistas do ensino fundamental $\left(6^{\circ}\right.$ ao $9^{\circ}$ ano) da rede de ensino de São Paulo, com o objetivo de compreender processos relacionais entre docentes e alunos, estes últimos imigrantes, no que concerne à alteridade no multiculturalismo.

Ambas as sessões foram facilitadas pela pesquisadora, que contou com o de relatoria de colegas. ${ }^{11}$ Foram feitos registros de áudio dos grupos focais, que foram transcritos com o intuito de favorecer a sistematização e a análise, que conjugaram o proposto por Marková et al. (2007) com a análise de conteúdo (FRANCO, 2008).

Das tabelas que seguem, constam os resultados sistematizados da análise de conteúdo das transcrições das sessões de grupo focal realizadas com onze professoras do ensino fundamental 2 , sendo que cinco professoras possuem mais de dez anos de docência e as seis outras professoras possuem mais de dez anos de experiência em sala de aula ${ }^{12}$. Elas são professoras de conteúdos curriculares diferentes, que envolvem $60 \%$ das disciplinas ministradas no fundamental 2. Quanto à formação das participantes da pesquisa, $80 \%$ delas fizeram sua graduação em faculdade particular, $30 \%$ delas possuem pós-graduação stricto sensu (nível mestrado) e $60 \%$ delas tiveram uma profissão anterior.

Foram identificadas cinco categorias de sentido associadas à tríade dialógica (MARKOVÁ, 2006, 2017). São elas: (1) ser professora; (2) alunos brasileiros versus alunos imigrantes; (3) conteúdos e metodologias de ensino; (4) fatores externos; (5) queixumes.

Da Tabela 1 consta a sistematização resultante da análise de conteúdo para o elemento da tríade "docente". O conteúdo "ser docente" emergiu dos diálogos entre as docentes nas duas sessões de grupo focal.

\footnotetext{
${ }^{10}$ Tradução livre de: "one of the main reasons for using focus groups to study social representations or socially shared knowledge is that they are comparable to ordinary talk. That is, they enable us to grasp the way in which different perspectives come into oppositions with each other, are negotiated and co-constructed".

${ }^{11}$ Nossos agradecimentos a Sandra Suely Lopes Souto da Silva e Martha Victoria Ribeiro Nunes.

${ }^{12}$ A variável tempo de docência foi destaque na análise, por evidenciar a configuração de perfis distintos de docentes e, por conseguinte, diferentes processos representacionais.
} 
Tabela 1 - Categoria 1 - "Ser professora"

\begin{tabular}{|c|c|c|c|}
\hline \multicolumn{4}{|c|}{ "SER PROFESSORA" } \\
\hline \multicolumn{4}{|c|}{$\begin{array}{l}\text { Relatos das respondentes sobre aspectos, atribuições, habilidades, sentimentos e ações do dia a dia } \\
\text { docente. }\end{array}$} \\
\hline Mais de 10 anos & $f$ & Menos de 10 anos & $f$ \\
\hline $\begin{array}{l}\text { Desafiador (desafio / responsabilidade / } \\
\text { estratégia de sobrevivência/ barreira). }\end{array}$ & 19 & $\begin{array}{l}\text { Desafiador (faz parte das nossas } \\
\text { atribuições). }\end{array}$ & 8 \\
\hline $\begin{array}{l}\text { Desgastante / estressante / desestimulante / } \\
\text { "é difícil". }\end{array}$ & 17 & $\begin{array}{l}\text { Difícil (perceber e salientar as dificuldades } \\
\text { do processo). }\end{array}$ & 2 \\
\hline Amar a profissão/ “é gostoso" / “é bom”. & 4 & Ter sensação de falta de preparo. & 4 \\
\hline Querer que o aluno aprenda. & 6 & $\begin{array}{l}\text { Prestar atenção na diversidade / } \\
\text { interculturalidade. }\end{array}$ & 6 \\
\hline Autopercepção autoritária. & 9 & Ser autoridade em sala. & 2 \\
\hline $\begin{array}{l}\text { Reconhecer a relação professor-aluno como } \\
\text { carinhosa (todos saem ganhando). }\end{array}$ & 10 & $\begin{array}{l}\text { Aprender todos os dias / ter novos } \\
\text { olhares. }\end{array}$ & 7 \\
\hline "Enjoei da docência" / "não faço mais nada". & 16 & Aprender com os alunos. & 2 \\
\hline "A conversa e a indisciplina incomodam". & 15 & $\begin{array}{l}\text { Docência compartilhada (com outros } \\
\text { professores). }\end{array}$ & 8 \\
\hline Passar, jogar, dar, trabalhar o conteúdo. & 12 & $\begin{array}{l}\text { Aprender / revisitar / rever / trocar / } \\
\text { "não ensinar" / participar / insistir. }\end{array}$ & 10 \\
\hline $\begin{array}{l}\text { A experiência nos torna "as professoras" ("as } \\
\text { novas não sofrem como a gente"). }\end{array}$ & 3 & $\begin{array}{l}\text { Experiência / vivência / conselhos } \\
\text { (professores mais experientes como } \\
\text { fontes). }\end{array}$ & 12 \\
\hline $\begin{array}{l}\text { Visão diferente das professoras mais novas em } \\
\text { relação a elas. }\end{array}$ & 9 & Reconhecer o protagonismo do aluno. & 9 \\
\hline \multirow[t]{2}{*}{ Ter "autocobrança”. } & 7 & $\begin{array}{l}\text { Ter inteligência emocional (sua e do } \\
\text { aluno). }\end{array}$ & 6 \\
\hline & & Ter "autocobrança". & 10 \\
\hline
\end{tabular}

Fonte: Dados da pesquisa.

As docentes com menos de 10 anos de experiência mostraram-se mais esperançosas e motivadas com a possibilidade de mudar a realidade social de seu alunado, e encaram os desafios como "parte do trabalho". Por outro lado, apresentaram certa insegurança sobre o fato de ainda faltar muito preparo para lidar com o cotidiano escolar. As professoras com menos tempo de experiência também pontuaram sobre os sistemas de avaliação, tanto no que concerne à avaliação do aluno quanto a avaliação dos docentes e da escola. Elas falavam com respeito e admiração das professoras mais experientes, sempre buscando pensar em projetos e soluções mais inclusivos para os alunos para os demais colegas. Destaca-se que elas se colocam no lugar de aprendizes e ressaltam que podem aprender juntas tanto com os alunos quanto com as professoras mais experientes. Essas professoras demonstram estar atentas à diversidade e declaram olhar o diferente como parceiro e não como uma barreira.

As professoras com mais de 10 anos de docência detalharam as dificuldades e angústias da sala de aula com palavras repletas de sentidos de desistência e às vezes saudosismo, juntamente com expressões de cansaço pelo olhar e suspiros. Muitas delas estavam sentadas nas cadeiras de maneira relaxada, mas com os braços "jogados" ao lado do corpo. Por várias vezes, utilizaram 
palavras que refletiam muito mais uma "educação bancária" do que uma "educação libertadora" (FREIRE, 2002). O amor à profissão foi dito timidamente, em contrapartida reiteradas vezes afirmaram o desgaste em ser professora.

No que concerne ao aluno, em ambos os grupos foi possível encontrar o binômio estudantes brasileiros e estudantes estrangeiros (imigrantes). Aos estudantes de origem boliviana foi dada ênfase nos diálogos em ambas as sessões (Tabela 2).

Tabela 2: Categoria 2 - Alunos brasileiros versus alunos estrangeiros

\begin{tabular}{|c|c|c|c|c|}
\hline \multicolumn{5}{|c|}{ ALUNOS BRASILEIROS VERSUS ALUNOS ESTRANGEIROS } \\
\hline \multicolumn{5}{|c|}{ A percepção das professoras em relação aos alunos brasileiros e os alunos imigrantes, notadamente bolivianos. } \\
\hline Docentes & “nossos" (alunos brasileiros) & $f$ & “eles" (alunos imigrantes) & $f$ \\
\hline \multirow{14}{*}{$\begin{array}{l}\text { Mais de } \\
10 \text { anos }\end{array}$} & "São educados" & & "São educados" & \\
\hline & $\begin{array}{l}\text { - Aluno tem inciativa / animados / } \\
\text { divertidos / amáveis. }\end{array}$ & 10 & • $\quad$ "Totalmente educados". & 4 \\
\hline & - $\quad$ Indisciplinados / desobedientes. & 10 & - $\quad$ Disciplinados / obedientes. & 4 \\
\hline & "Chegam sem material”. & 3 & $\begin{array}{l}\text { - "Trazem todo material" / "São } \\
\text { caprichosos com o material”. }\end{array}$ & 7 \\
\hline & "Não querem pensar". & 2 & $\begin{array}{l}\text { • "Aprendem mais" / "São mais } \\
\text { concentrados". }\end{array}$ & 7 \\
\hline & "Não recebe cobrança de casa" & 3 & $\begin{array}{l}\text { "Quando tem problema e chama os pais, dá } \\
\text { resultado" }\end{array}$ & 3 \\
\hline & Relacionamento distante com a família. & 3 & "Valorizam bastante a família". & 6 \\
\hline & $\begin{array}{l}\text { "Os brasileiros não ajudam os imigrantes } \\
\text { nas tarefas". }\end{array}$ & 1 & $\begin{array}{l}\text { "Não tem esse movimento de tentar ajudar } \\
\text { os brasileiros". }\end{array}$ & 2 \\
\hline & Linguagens: & & Linguagens: & \\
\hline & $\begin{array}{l}\text { - Língua portuguesa: dificuldade e } \\
\text { interesse. }\end{array}$ & 4 & Língua portuguesa: dificuldade. & 4 \\
\hline & - $\quad$ Expressão oral: teatro. & 5 & Expressão oral: teatro. & 2 \\
\hline & Matemática: resistência. & 6 & - $\quad$ Matemática: facilidade. & 5 \\
\hline & - $\quad$ Expressão artística: resistência. & 3 & $\begin{array}{l}\text { - Expressão artística: "desenham } \\
\text { muito bem". }\end{array}$ & 6 \\
\hline & "Os brasileiros se juntam para bagunçar" & 5 & $\begin{array}{l}\text { "Eles preferem ficar entre eles para se } \\
\text { proteger": são tímidos / retraídos / são } \\
\text { fechados. }\end{array}$ & 17 \\
\hline \multirow{6}{*}{$\begin{array}{l}\text { Menos de } \\
10 \text { anos }\end{array}$} & Se consideram "os normais". & 3 & "Os alunos bolivianos são diferentes". & 8 \\
\hline & $\begin{array}{l}\text { Apresentam comportamentos ligados à } \\
\text { xenofobia/preconceito. }\end{array}$ & 6 & $\begin{array}{l}\text { "São super retraídos" } \\
\text { culturas diferentes) }\end{array}$ & 9 \\
\hline & $\begin{array}{l}\text { As famílias dos brasileiros apresentam } \\
\text { resistência aos imigrantes. }\end{array}$ & 4 & $\begin{array}{l}\text { "Os alunos imigrantes se sentem em um } \\
\text { ambiente não acolhedor" / vítimas da } \\
\text { vulnerabilidade social. }\end{array}$ & 8 \\
\hline & Dificuldade de concentração. & 2 & Mais concentrados e mais dedicados. & 4 \\
\hline & $\begin{array}{l}\text { Comunicação violenta entre eles (uso de } \\
\text { palavrões). }\end{array}$ & 3 & Dificuldade de entender nossa língua. & 8 \\
\hline & Mais falantes e mais agitados. & & & 9 \\
\hline
\end{tabular}

Fonte: Dados da pesquisa. 
As professoras com mais de 10 anos de docência elogiaram o comportamento e a participação das famílias dos alunos imigrantes. Elas ressaltaram a habilidade dos estudantes estrangeiros em expressão artística, em especial com o desenho e com a estética das cores. O grupo de professoras com menos experiência docente compreende que ambos os grupos de estudantes são "normais" (diferente da percepção das professoras do outro grupo, que creem que há algo de errado com os alunos brasileiros), mas que os brasileiros são mais participativos. Por outro lado, referiram-se aos estudantes imigrantes a todo tempo como "eles". Ressaltaram que os "colegas [alunos] brasileiros" apelidam pejorativamente os alunos imigrantes, o que gera, como consequência, isolamento a ponto de os estrangeiros não prestarem ajuda caso os colegas brasileiros necessitem. Entre as meninas há um pouco mais de entrosamento entre as "colegas brasileiras" e as imigrantes. Nos relatos das professoras e nas observações assistemáticas foi possível contemplar essa diferença.

No que concerne às metodologias de ensino e aos conteúdos, foi identificada distinção marcante entre os grupos (Tabela 3).

Tabela 3 - Categoria 3 - Conteúdos e metodologias de ensino

\begin{tabular}{|l|c|l|c|}
\hline \multicolumn{4}{|c|}{ CONTEÚDOS E METODOLOGIAS DE ENSINO } \\
\hline \multicolumn{2}{|c|}{ Relatos da visão das participantes sobre a prática da sala de aula } \\
\hline \multicolumn{1}{|c|}{ Mais de 10 anos } & $f$ & \multicolumn{1}{c|}{ Menos de 10 anos } & $f$ \\
\hline Ênfase no conteúdo. & 27 & $\begin{array}{l}\text { Ênfase na cooperação e docência compartilhada } \\
\text { (ensino seriado). }\end{array}$ & 16 \\
\hline Copiar do quadro. & 6 & "Não está só reproduzindo o conteúdo". & 4 \\
\hline Enfase nas avaliações e provas. & 4 & "A avaliação precisa mudar". & 4 \\
\hline $\begin{array}{l}\text { Verbos empregados: passar, jogar, dar, } \\
\text { trabalhar o conteúdo. }\end{array}$ & 23 & $\begin{array}{l}\text { Verbos empregados: aprender, revisitar, rever, } \\
\text { trocar, não ensinar, participar. }\end{array}$ & 18 \\
\hline $\begin{array}{l}\text { Ignorar o que o aluno quer ("às vezes é } \\
\text { quase um grito de socorro" dos professores }\end{array}$ & 13 & "Falta o principal: que é o aluno participar". & 3 \\
\hline "Guarda o celular" & 3 & Projetos interdisciplinares. & 6 \\
\hline & & Deixar com o celular. & 1 \\
\hline
\end{tabular}

Fonte: Dados da pesquisa.

Enquanto as docentes mais experientes enfatizaram o conteúdo, as professoras com menos tempo de docência falaram de alternativas, novos métodos, projetos de integração tanto de alunos quanto de professores. Os verbos empregados pelos dois grupos também foram distintos. Enquanto as mais experientes empregam os verbos "dar", "cobrar", "passar” e "jogar" o conteúdo, as menos experientes usaram um vocabulário associado a "aprender" e "reavaliar". As professoras menos experientes recorrem à tecnologia, a exemplo do celular, como ferramentas de aprendizagem, ao passo que as com mais tempo de docência proíbem o celular em sala de aula, 
reivindicando uma posição de protagonismo e autoridade. As com menos de 10 anos de magistério afirmaram que o protagonismo deve ser do aluno, e que elas precisam ser as facilitadoras deste processo. Pelos diálogos foi possível inferir que elas ousavam mais (por exemplo, desenvolviam atividades fora da sala de aula), enquanto as mais experientes relataram que "hoje em dia" não é mais possível fazer estas atividades.

Frases que expressaram frustração e que evidenciaram um sentimento de impotência estavam presentes nas duas sessões de grupo focal, caracterizando um padrão de queixume, razão pela qual compuseram a categoria 4 , sistematizada na Tabela 4 .

Tabela 4 - Categoria 4 - Queixumes

\begin{tabular}{|l|c|l|c|}
\hline \multicolumn{1}{|c|}{ QUEIXUMES } \\
\hline \multicolumn{1}{|c|}{ Mais de 10 anos } & $f$ & \multicolumn{1}{c|}{ Menos de 10 anos } & $f$ \\
\hline $\begin{array}{l}\text { Distanciamento em relação aos alunos como } \\
\text { "estratégia de sobrevivência" (a aula deve ser } \\
\text { para os que "querem", não para todos). }\end{array}$ & 14 & "Tá muito difícil". & 7 \\
\hline Desgaste, estresse, cansaço. & 26 & $\begin{array}{l}\text { Desespero; "Não sei nada, pra mim é tudo } \\
\text { novo". }\end{array}$ & 5 \\
\hline "Eu não consigo". & 11 & "Não vou conseguir". & 6 \\
\hline & & "Sala de aula muito cheia só atrapalha". & 5 \\
\hline
\end{tabular}

Fonte: Dados da pesquisa.

A quinta e última categoria que emergiu das análises está associada aos fatores externos que, de alguma maneira, intervêm nos processos de ensino e de aprendizagem. Os conteúdos que compuseram essa categoria temática foram encontrados nos diálogos das duas sessões de grupo focal e foram sistematizados na Tabela 5 .

Tabela 5 - Categoria 5 - Fatores externos aos processos de ensino e de aprendizagem

\begin{tabular}{|l|l|c|l|l|}
\hline \multicolumn{5}{|c|}{ FATORES EXTERNOS AOS PROCESSOS DE ENSINO E DE APRENDIZAGEM } \\
\hline \multicolumn{2}{|c|}{ A descrição dos professores quanto aos fatores que intervêm nos processos de ensino e aprendizagem. } \\
\hline \multicolumn{2}{|c|}{ Docentes } & \multicolumn{1}{|c|}{ Fatores facilitadores } & $f$ \\
\hline \multirow{2}{*}{$\begin{array}{l}\text { Mais de } \\
\text { Anos }\end{array}$} & Casa, família. & 8 & Casa, família. & 3 \\
\cline { 2 - 6 } & Estrutura da escola. & 3 & Estrutura da escola. & 2 \\
\cline { 2 - 6 } & Diretoria de ensino. & 1 & Coordenadora. & 1 \\
\hline \multirow{2}{*}{\begin{tabular}{l} 
Menos de anos \\
\cline { 2 - 5 }
\end{tabular}} & Currículo. & 8 & Currículo. & 1 \\
\cline { 2 - 5 } & Casa / Família. & 9 & & \\
\cline { 2 - 5 } & Diretoria de ensino. & 3 & & \\
\hline
\end{tabular}

Fonte: Dados da pesquisa. 
Os fatores externos que intervêm, facilitando ou inibindo os processos de ensino e de aprendizagem estavam presentes no discurso dos dois grupos. Algo que ficou notório no discurso das professoras com mais de dez anos de docência é que a família é essencial para o sucesso do aluno. Elas ressaltaram que a contribuição das famílias dos imigrantes é muito mais presente do que a dos brasileiros. Por sua vez, as professoras com menos tempo de docência, além de terem reforçado que as famílias são peças-chave para o bom desenvolvimento dos processos de ensino e de aprendizagem, afirmaram que a pressão da diretoria da escola e da Secretaria de Educação em relação aos resultados nas avaliações externas são fatores que atrapalham o que elas gostariam de propor para ser desenvolvido com os alunos. Essas professoras também relataram que o currículo precisa ser reformulado e adaptado para a realidade dos alunos.

\section{Considerações permitidas}

As representações sociais sobre os alunos imigrantes foram se evidenciando nos discursos das docentes em confrontação com as representações sobre os estudantes brasileiros, e jogam luz, sobretudo, nos alunos de origem boliviana. As ações, reações, discursos, atitudes e leituras de mundo estavam imbricadas de representações que permeiam não somente o dia a dia das relações, mas avançam até as práticas de ensino.

Nesse tocante, fez-se perceber o emprego por parte das docentes da palavra "nós", associada aos brasileiros, e da palavra "eles", associada aos imigrantes. No entanto, as dinâmicas de identidade e alteridade vinculadas ao emprego do "nós" versos eles", estão carregadas, em especial no grupo com mais tempo de docência, de uma idealização positiva, em relação aos alunos imigrantes, e negativa, em relação aos brasileiros.

Os diálogos entre as professoras permitiram identificar que os alunos imigrantes são mais "comportados", "dedicados", "organizados", "mantém o material limpo", e contam com o apoio do contexto familiar. A despeito das dificuldades com a língua portuguesa, destacam-se dos estudantes brasileiros no que se refere a outras linguagens, como a matemática e a artística (em especial o desenho).

A Emef abriga um projeto de integração entre os estudantes "Projeto de intercâmbio entre culturas, línguas e pessoas", muito bem avaliado entre os docentes e alunos. No entanto, esse projeto tem capacidade limitada e conhecimentos sobre alteridade, multiculturalismo e atividade docente foram requeridos pelas participantes de ambos os grupos focais, numa perspectiva de instrumentalização no âmbito escolar para processos que dizem respeito a diálogos, métodos, 
práticas, experiências e inclusão. Nesse sentido, ações que articulem a dialogicidade, na teoria das representações sociais e na pedagogia freireana, oferecem potencial à práxis educativa.

\section{Referências}

ALVES-MAZZOTTI, Alda; GEWANDSZNAJDER, Fernando. O método nas ciências naturais e sociais: pesquisa quantitativa e qualitativa. São Paulo: Pioneira, 2001.

ARRUDA, Angela. Representando a alteridade. Petrópolis: Vozes, 2002.

BAILEY, Alison L.; OSIPOVA, Anna V. Children's Multilingual Development and Education: fostering linguistic resources in home and school contexts. United Kingdom. Cambridge University Press, 2016.

BARBOSA, Joaquim Gonçalves. O diário de pesquisa: o estudante universitário e seu processo formativo. Brasília: Liber Livro, 2010.

BRASIL. Ministério da Educação. Instituto Nacional de Estudos e Pesquisas Educacionais Anísio Teixeira. Relatório de atividades Inep 2020. Brasília: Inep, 2021.

CANDAU, Vera M. Ferrão. Sociedade, cotidiano escolar e cultura(s): uma aproximação. Educação \& Sociedade, São Paulo, v. 23, n. 79, p. 125-161, ago. 2002.

CANEN, Ana. O multiculturalismo e seus dilemas: implicações na educação. Dossiê Educação e Desenvolvimento. Comunicaçãoepolítica, v. 25, n. 2, p. 91-107, 2015.

CANEN, Ana; CANEN, Alberto Gabbay. Rompendo fronteiras curriculares: multiculturalismo na Educação e outros campos de saber. Revista Currículo sem Fronteiras, v. 5, n. 2, p. 40-49, 2005.

CARRERAS, María Paula et al. Paro docente y representaciones sociales estudiantiles en la universidad Tucumana-Argentina. Revista@mbienteeducação, [S.1.], v. 10, n. 1, p. 9 - 24, jan. 2017. Disponível em: http://publicacoes.unicid.edu.br/index.php/ambienteeducacao/article/view/33. Acesso em: 17 mar. 2019. https://doi.org/10.26843/ae19828632v10n12017p9a24.

CAVALCANTI, Leonardo; OLIVEIRA, Tadeu Antonio; MACEDO, Marília. Imigração e Refúgio no Brasil. Relatório Anual 2020. Série Migrações. Observatório das Migrações Internacionais; Ministério da Justiça e Segurança Pública/ Conselho Nacional de Imigração e Coordenação Geral de Imigração Laboral. Brasília, DF: OBMigra, 2020.

FRANCO, Maria Laura Puglisi Barbosa. Análise de conteúdo. 3. ed. Brasília: Líber Livro, 2008.

FREIRE, Paulo. Pedagogia do Oprimido. 43. ed. Rio de Janeiro: Paz e Terra, 2005.

FREIRE, Paulo. Pedagogia da Esperança: um reencontro com a pedagogia do oprimido. 4. ed. Rio de Janeiro: Paz e Terra, 1997.

FREIRE, Paulo. Pedagogia da autonomia. 25. ed. São Paulo: Paz e Terra, 2002. 
FREIRE, Paulo. Educação e Mudança. 12. ed. Rio de Janeiro: Paz e Terra, 2006.

GONÇALVES, Alberto Oliveira; SILVA, Petronilha Beatriz Gonçalves e. O jogo das diferenças: o multiculturalismo e seus contextos. Belo Horizonte: Autêntica, 2001.

HOOKS, Bell. Ensinando a transgredir: a educação como prática da liberdade. São Paulo: Martins Fontes, 2013.

HOWARTH, Caroline; ANDREOULI, Eleni. 'Changing the context': tackling discrimination at school and in society. International Journal of Educational Development, v. 41, p. 184-191, Mar. 2015. Disponível em:

https://www.sciencedirect.com/science/article/abs/pii/S0738059314000510?via\%3Dihub. Acesso em: 14 mar. 2019.

JODELET, Denise. A alteridade como produto e processo psicossocial. In: ARRUDA, Angela. Representando a alteridade. Petrópolis: Vozes, 2002.

JODELET, Denise; TAPIA, Alfredo. Develando la cultura: estudios en representaciones sociales. México: Universidad Nacional Autónoma de Mexico, Facultad de Psicología, 2000.

MCLAREN, Peter. Escrevendo das margens: geografias de identidade, pedagogia e poder. In:

MCLAREN, Peter; GIROUX, Henry. Multiculturalismo revolucionário: pedagogia do dissenso para o novo milênio. Porto Alegre: ArtMed, 2000. p. 25-50.

MCLAREN, Peter. A vida nas escolas: uma introdução à pedagogia crítica nos fundamentos da educação. Porto Alegre: Artes Médicas, 1997.

MARKOVÁ, Ivana. Dialogicidade e Representações Sociais: as dinâmicas da mente. Petrópolis: Vozes, 2006.

MARKOVÁ, Ivana. Mente dialógica: senso comum e ética. São Paulo: Fundação Carlos Chagas; Curitiba: PUCPRess, 2017.

MARKOVÁ, Ivana et al. A. Dialogue in Focus Groups: exploring socially shared knowledge. Sheffield, Equinox, 2007.

MOSCOVICI, Serge. Representações sociais: investigações em psicologia social. 10 ed. Petrópolis: Vozes, 2013.

NOVAES, Adelina de Oliveira. Subjetividade social docente: elementos para um debate sobre "políticas de subjetividade". Cadernos de Pesquisa, São Paulo, v. 45, n. 156, p. 100-115, abr./jun. 2015.

NOVAES, Adelina de Oliveira. Brasil: representações sociais de estudantes de pedagogia. Dissertação (Mestrado em Psicologia) - Pontifícia Universidade Católica de São Paulo, São Paulo, 2006. 
NOVAES, Adelina; ORNELLAS, Maria de Lourdes; ENS, Romilda Teodora. Convergências teóricas em representações sociais e seu aporte para o estudo de políticas docentes. Revista Diálogo Educacional, v. 17, n. 53, ago. 2017.

SÃO PAULO (ESTADO). Secretaria do Estado da Educação. Infográfico de alunos estrangeiros na rede estadual de ensino. São Paulo. 2019. Disponível em:

https:/ / www.educacao.sp.gov.br/infografico-alunos-estrangeiros-na-rede-estadual-de-ensino/. Acesso em: 28 jun. 2021.

SÃO PAULO (MUNICÍPIO). Secretaria Municipal de Educação 2017. Microdados da Rede Municipal de Educação. São Paulo, 2017. Disponível em:

http://dados.prefeitura.sp.gov.br/dataset/microdados-matriculas. Acesso em: 05 jul. 2021.

SILVA, Maria José Albuquerque; BRANDIM, Maria Rejane L. Multiculturalismo e Educação: em defesa da diversidade cultural. Diversa, v. 1, n. 1, p. 51-66, jan./jun. 2008. 